\title{
Ekstraksi dan Identifikasi Kandungan Metabolit Fraksi Diklorometana dan Aquades Ekstrak Metanol Daun Sirsak (Annona Muricata Linn)
}

\section{Noviana M Obenu}

Fakultas Pertanian, Universitas Timor, Kefamenanu, TTU - NTT, Indonesia, email: noviobenu3@gmail.com

\section{Article Info}

Article history:

Received 10 Juni 2019

Received in revised form 20 Juni 2019

Accepted 28 Juni 2019

DOI:
https://doi.org/10.32938/slk.v2i1.717

Keywords:

Keywords:

Ekstraksi

Ekstraksi

Annona muricata Linn metabolit

\section{Abstrak}

Sirsak adalah salah satu tumbuhan yang banyak dijumpai di daerah Nusa Tenggara Timur (NTT). Beberapa bagian tumbuhan sirsak diketahui telah banyak dimanfaatkan sebagai pengobatan tradisional ataupun sebagai peptisida alami. Pemanfaatan tumbuhan ini tidak terlepas dari senyawa bioaktif yang terkandung di dalamnya. Senyawa - senyawa tersebut akan berhasil diisolasi tergantung pemilihan pelarut. Penelitian ini dilakukan dengan tujuan mengetahui kandungan senyawa metabolit yang terkandung dalam setiap pelarut yang digunakan. Langkah-langkah penelitian ini meliputi preparasi sampel daun sirsak, ekstraksi secara maserasi dengan pelarut metanol, partisi ekstrak metanol dengan pelarut diklorometana dan air serta identifikasi komposisi metabolit dengan instrumen kromatografi cair kinerja tinggi (KCKT). Senyawa-senyawa yang teridentifikasi pada KCKT pelarut diklorometana diduga adalah senyawa metabolit golongan fenol, polikatida, tannin dan alkaloid, sedangkan senyawa yang teridentifikasi KCKT pada pelarut air diduga adalah senyawa polar yang terikat dengan suatu gugus glikosida.

\section{PENDAHULUAN}

Metabolit merupakan berbagai senyawa yang terbentuk dalam proses metabolisme. Metabolisme sendiri adalah semua reaksi kimia yang terjadi di dalam organisme atau makluk hidup. Berdasarkan pembentukannya metabolit terbagi atas dua bagian yaitu metabolit primer yang berpengaruh langsung terhadap tumbuh kembang suatu organisme dan metabolit sekunder yang digunakan organisme untuk berinteraksi dengan lingkungannya (Harborne, 1993). Senyawa metabolit sekunder merupakan senyawa kimia yang umumnya mempunyai kemampuan bioaktivitas yakni kemampuan suatu senyawa menghasilkan aktifitas biologis atau senyawa yang dapat digunakan untuk menyembuhkan suatu penyakit. Tumbuhan sirsak (Annona muricata L.) merupakan tumbuhan yang tidak sulit dijumpai terutama di NTT. Tumbuhan sirsak berasal dari Karibia, Amerika Tengah dan Amerika Selatan. Di Negara India dan Afrika tumbuhan sirsak telah banyak digunakan sebagai pengobatan tradisional (Bories et al, 1990), bagian-bagian tumbuhan sirsak yang digunakan antara lain bunga, daun, buah, kulit dan akar (Moghadamtousi et al, 2015). Selain itu, tumbuhan sirsak juga dimanfaatkan pada sektor pertanian yakni sebagai pengendali hama pada sayuran (Tenrirawe et al, 2011) dan tanaman cabai (Salaki et al, 2012); (Astuti et al, 2014).

Penelitian awal senyawa-senyawa metabolit pada daun sirsak dilakukan (Zeng et al, 1996) dan berhasil mengisolasi lima senyawa yang tergolong kelompok senyawa polikatida. Selanjutnya Kim (1998), juga berhasil mengisolasi dua senyawa yakni muricoreacin dan murihexosin. Liaw (2001) melakukan penelitian senyawa pada daun sirsak dan berhasil mengisolasi tiga (3) senyawa baru yakni muricin $\mathrm{H}$ dan senyawa-senyawa acetogenin yang telah diketahui yakni annonacin, annonacinone, annomontacin, murisolin dan xylomaticin. Penelitian akhir dilakukan Chang (2003) dan berhasil mengisolasi dua senyawa baru pada daun sirsak yaitu Annocatin A dan Annocatin B. Senyawa yang berhasil diisolasi memiliki bioaktivitas terhadap berbagai penyakit (Kim et al, 1998); (Zeng et al, 1996); (Chang et al, 2003).

Secara kemotaksonomi afinitas kimiawi satu spesies dalam satu genus atau satu famili mempunyai pola pembentukan struktur molekul yang sama. Pembentukan pola struktur ini secara kualitatif mengandung senyawa-senyawa yang sama, akan tetapi kuantitas masing-masing senyawa dapat berbeda. Faktor - faktor yang kemungkinan berpengaruh pada perbedaan ini antara lain pengaruh lingkungan di mana tumbuhan itu tumbuh, bagian tumbuhan tersebut dan letak geografis suatu wilayah (Venkataraman, 1972).

Kelarutan setiap metabolit yang terkandung dalam tumbuh tumbuhan tergantung dari kepolaran setiap pelarut yang digunakan untuk mengekstrak dan mengisolasi. Sebagian metabolit akan larut dalam pelarut polar dan sebagiannya lagi akan larut dalam pelarut non polar (like dissolve like). Salah satu kendala dalam pemanfaatan ekstrak daun sirsak adalah kurang efisiennya pelarut yang digunakan selama ini. Oleh karena itu perlu dilakukan penelitian ekstraksi senyawa-senyawa metabolit dalam daun tumbuhan sirsak menggunakan pelarut polar dan dilanjutkan dengan partisi pelarut menggunakan dua pelarut yang berbeda tingkat kepolarannya (Fessenden, 1997).

\section{METODE PENELITIAN}

\section{1.Waktu dan tempat penelitian}

Penelitian dilakukan pada bulan Januari 2018 - Mei 2018 dilaksanakan di Laboratorium Kimia Fakultas Sains dan Teknik Universitas Nusa Cendana, Kupang. Analisis komposisi senyawa dengan Kromatografi Cair Kinerja Tinggi (KCKT) dilaksanakan di Badan Pengawasan Obat dan Makanan (BPOM) Kupang, Evaporasi dilaksanakan di Laboratorium Pendidikan Biologi Fakultas Matematika dan Ilmu Pengetahuan Alam Universitas Katolik Widya Mandiri (UNIKA) Kupang.

\section{2. Bahan dan Alat}

Bahan-bahan yang digunakan dalam penelitian ini adalah Daun Sirsak, Metanol, Aquades, Diklorometana, Kertas Saring, padatan $\mathrm{I}_{2}$, Alumunium Foil.

Alat-alat yang digunakan dalam penelitian yakni Corong Pisah, Gelas Kimia, Gelas Ukur, Corong Biasa, Neraca Analitik, Tabung Reaksi, Kertas Label, Pengaduk, Seperangkat Alat Evaporator, Pipet Tetes, Seperangkat Alat Blender, Seperangkat Alat Kromatografi Cair Kinerja Tinggi (KCKT).

\section{3. Prosedur Percobaan}

Pengambilan sampel daun sirsak dilakukan di Desa Nifuboke, Kecamatan Noemuti, Kabupaten Timor Tengah Utara (TTU). Sampel daun sirsak yang digunakan tidak memperhitungkan umur dari tumbuhan sirsak dan waktu pengambilan. Selanjutnya dilakukan preparasi sampel dengan cara daun sirsak ditimbang sebanyak $7 \mathrm{~kg}$ daun sirsak segar, dan kemudian dicuci sampai bersih untuk menghilangkan pengotor dan dikeringanginkan pada suhu ruang. Setelah kering, sampel diblender sampai diperoleh serbuk. Serbuk yang diperoleh ditimbang dan disimpan dalam kantong plastik.

Tahap berikut adalah melakukan ekstraksi daun sirsak dengan pelarut metanol. Langkah-langkahnya adalah 50 gr tepung/serbuk sirsak ditimbang dan dimasukkan dalam erlenmeyer $1000 \mathrm{~mL}$. Kedalam erlenmeyer yang berisi serbuk daun sirsak, dimasukkan metanol $500 \mathrm{~mL}$ dengan hati-hati kemudian diaduk sampai semua tepung sirsak terendam pelarut metanol. Erlenmeyer yang berisi larutan ditutup rapat dan dibiarkan selama 1x24 jam kemudian disaring dengan kertas saring whatman 42. Filtrat yang diperoleh diuapkan pada suhu $55^{\circ} \mathrm{C}$ dengan rotary evaporator. Ekstrak yang diperoleh disimpan pada botol kemudian ditutup rapat. Selanjutnya dilakukan identifikasi kandungan metabolit ekstrak metanol daun sirsak dengan cara menimbang \pm 2.5 gr ekstrak pekat methanol daun sirsak, kemudian dianalisis dengan Kromatografi Cair Kinerja Tinggi (KCKT).

Selain itu, tahap partisi pelarut ekstrak metanol daun sirsak, dilakukan dengan cara menimbang \pm 2.5 gr ekstrak pekat metanol sirsak, dimasukkan dalam gelas kimia ditambahkan $10 \mathrm{~mL}$ air aquades kemudian dilarutkan sampai homogen lalu dipindahkan larutan di atas ke dalam corong pisah dengan hati-hati (bilas residu dengan aquades sampai volume akhir $20 \mathrm{~mL}$ ). Selanjutnya, ditambahkan berturut-turut $4 \times 25 \mathrm{~mL}$ pelarut diklorometana kemudian dikocok sehingga diperoleh dua lapisan yang tidak saling bercampur. Lapisan bawah selanjutnya dikeluarkan dan ditampung dalam suatu wadah. Fraksi aquades yang masih tersisa dikeluarkan dan ditampung pada satu wadah, selanjutnya fraksi diklorometana hasil partisi dievaporasi pada titik didih $20^{\circ} \mathrm{C}$ dan diperoleh ekstrak hasil partisi. Fraksi air dibekukan pada suhu suhu rendah selama 2 jam, kemudian dipisahkan. Kandungan senyawa fraksi diklorometana dan aquades diidentifiksi dengan Kromatografi Cair Kinerja Tinggi (KCKT).

\section{HASIL DAN PEMBAHASAN}

\section{a. Preparasi sampel}

Daun sirsak yang digunakan dalam penelitian ini adalah daun yang tidak terlalu muda dan tidak terlalu tua, jika dihitung pada satu dahan daun yang diambil kira-kira daun ke 4-7. Sampel daun sirsak yang sudah dipetik, dicuci untuk menghilangkan pengotor seperti debu yang menempel pada daun. Sampel kemudian dikeringanginkan. Pengeringan dilakukan untuk mengurangi kadar air sehingga tidak terjadi reaksi enzimatis, pertumbuhan jamur dan mempermudah penggilingan. Sampel yang telah kering kemudian diblender untuk memperluas bidang permukaan serta membantu pemecahan dinding dan membran sel sehingga mempermudah 
proses ekstraksi. Sampel yang telah diblender ditimbang dan diperoleh berat totalnya $5 \mathrm{~kg}$. Sampel kering yang diperoleh dalam bentuk serbuk berwarna hijau selanjutnya disimpan dalam plastik (Harborne, 1993), (Kristanti et all, 2008)

\section{b. Ekstraksi Sampel}

Serbuk daun sirsak diekstraksi secara dingin yakni dengan cara dimaserasi. Langkah ini lebih diminati karena lebih mudah, murah dan tidak merusak suatu struktur senyawa apabila struktur tersebut tidak tahan panas. Ekstraksi dilakukan untuk menarik atau memisahkan senyawa-senyawa dari suatu sampel/analit menggunakan pelarut. Serbuk daun sirsak dimaserasi dengan metanol selama 1x24 jam. Semakin lama suatu sampel diekstraksi maka hasil ekstrak yang diperoleh akan lebih banyak jumlahnya. Ekstraksi yang optimal jika dilakukan berulang-ulang pada suatu sampel (Siswarni et al, 2016), (Sumantri et al, 2014). Pemilihan metanol sebagai pelarut dalam proses maserasi disebabakan karena metanol adalah salah satu pelarut organik yang umum dan mampu melarutkan semua senyawa metabolit dalam tumbuhan. Selain metanol dapat juga digunakan pelarut yang kepolarannya hampir sama misalnya etanol (Kim et al, 1998), (Zeng et al, 1996)

Hasil maserasi yang diperoleh kemudian disaring untuk memisahkan residu dan filtrat. Filtrat yang diperoleh kemudian dievaporasi pada suhu $55^{\circ} \mathrm{C}$. Evaporasi berfungsi untuk mempermudah proses penguapan pelarut dengan memperkecil tekanan dalam vakum dan temperatur diatur di bawah titik didih pelarut. Hasil evaporasi diperoleh ekstrak metanol dengan berat 51 gr (250 gr sampel dan 2,5 liter metanol). Ekstrak pekat ini selanjutnya dianalisis dengan kromatografi cair kinerja tinggi (KCKT) untuk mengetahui total senyawa-senyawa yang terekstrak dalam pelarut metanol dan besarnya konsentrasi setiap senyawa. Ekstrak metanol selanjutnya dipartisi dengan pelarut aquades dan diklorometana didasarkan pada kelarutan dan kepolaran senyawa-senyawa dalam pelarut (like dissolve like) (Zeng et al, 1996); (Kim et al, 1998).

c. Hasil Identifikasi Kandungan Metabolit dalam Ekstrak Metanol Daun Sirsak (Total) menggunakan Kromatografi Cair Kinerja Tinggi (KCKT) Identifikasi komposisi metabolit dalam ekstrak metanol dengan KCKT dilakukan agar diketahui jumlah senyawa total dalam ekstrak metanol dan konsentrasi setiap senyawa. Hasil analisis ekstrak metanol daun sirsak menggunakan kromatografi cair kinerja tinggi mencatat adanya 7 peak yang teridentifikasi dalam ekstrak metanol seperti terlihat pada Gambar 1.

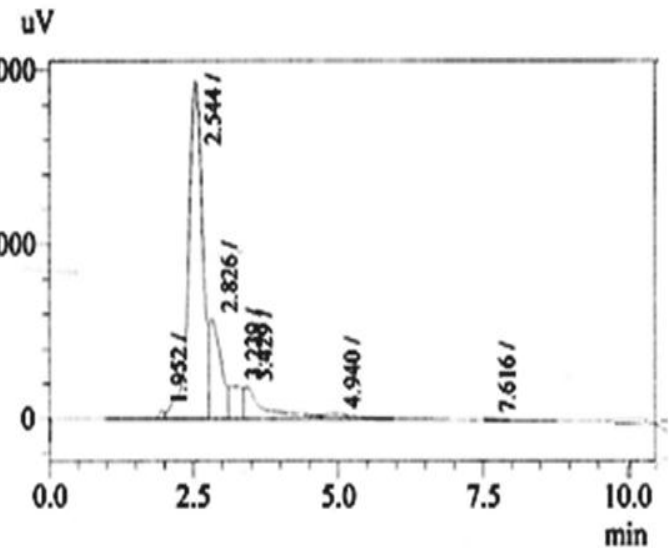

Gambar 1. Kromatogram hasil identifikasi senyawa total dalam pelarut $\mathrm{MeOH}$

Peak-peak yang tampak pada hasil pemisahan KCKT dan waktu retensi masing-masing di atas terlihat bahwa peak ke 2 dan 3 (Rt 2,544 dan 2,826) merupakan komponen paling dominan dalam ekstrak metanol dengan konsentrasi $66,449 \%$ dan $15,986 \%$. Peak yang dominan pada hasil identifikasi esktrak metanol ini diduga kemungkinan termasuk senyawa atau metabolit yang tergolong polar.

\section{d. Partisi pelarut diklorometana dan Aquades}

Ekstrak metanol daun sirsak, selanjutnya dipartisi menggunakan dua pelarut yakni diklorometana $\left(\mathrm{CH}_{2} \mathrm{Cl}_{2}\right)$ dan aqudes $\left(\mathrm{H}_{2} \mathrm{O}\right)$. Kedua pelarut ini memiliki sifat kepolaran yang berbeda, sehingga diasumsikan bahwa setiap metabolit akan larut pada masing-masing pelarut berdasarkan kepolarannya (Sumantri et al, 2014). Langkah awal dilakukan dengan melarutkan ekstrak metanol dalam aquades kemudian dipindahkan ke corong pisah dan ditambahkan berturut-turut 4x25 ml $\mathrm{CH}_{2} \mathrm{Cl}_{2}$. Penambahan diklorometana dilakukan secara berturut-turut agar senyawa dalam ekstrak lebih terekstraksi dengan baik (Siswarni et al, 2016). Setelah itu didiamkan beberapa saat \pm 30 menit sampai terbentuk lapisan dan selanjutnya lapisan tersebut dipisahkan berdasarkan berat jenis tiap pelarut.
Pelarut diklorometana memiliki massa jenis $(1,326 \mathrm{gr} / \mathrm{ml})$ lebih besar dari air $(1,000 \mathrm{gr} / \mathrm{ml})$ sehingga lapisannya berada dibagian bawah. Hasil partisi dengan pelarut aquades dan diklorometana, selanjunya dievaporasi untuk menghilangkan pelarutnya dan di analisis dengan KCKT.

e. Hasil identifikasi kandungan metabolit ekstrak diklorometana dan aquades dengan KCKT

Hasil Identifikasi komponen metabolit dalam fraksi aquades dan diklorometana menggunakan KCKT dilakukan untuk mengetahui jumlah senyawa yang larut dalam masing-masing fraksi dan ditampilkan dalam bentuk puncak - puncak pada rekorder. Lebar puncak dan tinggi puncak sebanding dengan konsentrasi. Hasil identifikasi menggunakan KCKT mencatat adanya 11 peak teridentifikasi dalam fraksi diklorometana terlihat pada Gambar 2, sedangkan fraksi aquades teridentifikasi 4 peak terlihat pada Gambar 3.

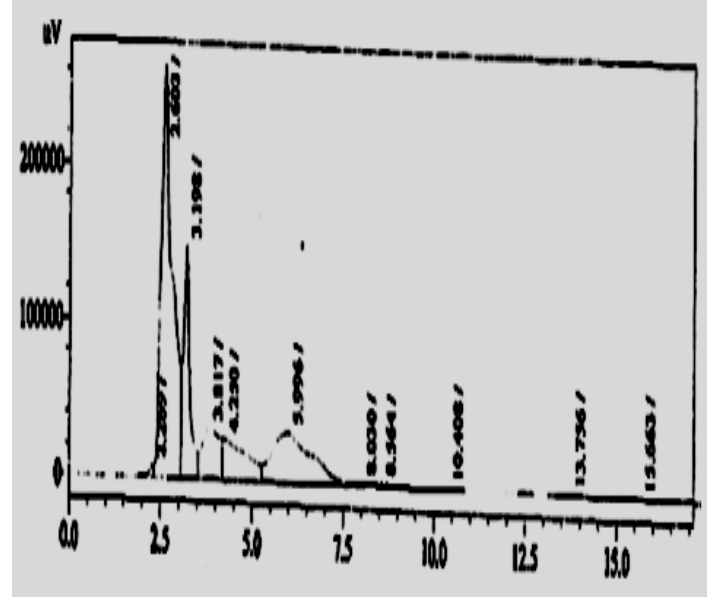

Gambar 2. Kromatogram hasil identifikasi senyawa dalam pelarut $\mathrm{CH}_{2} \mathrm{Cl}_{2}$

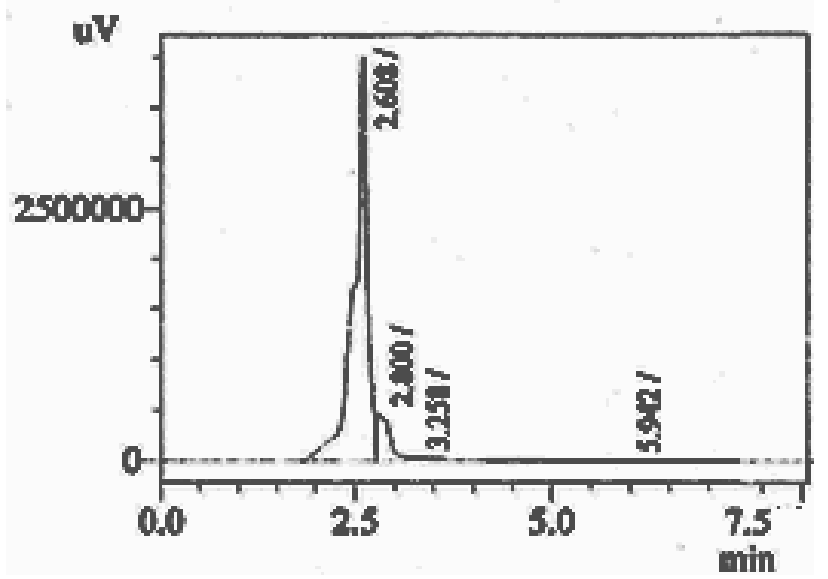

Gambar 3. Kromatogram hasil identifikasi senyawa pelarut $\mathrm{H}_{2} \mathrm{O}$

Peak-peak yang teridentifikasi dalam fraksi diklorometana memperlihatkan bahwa peak ke 2, 3 dan 6 merupakan komponen paling dominan dengan presentase berturut-turut $45,01 \%, 14,49 \%$ dan $21,12 \%$, sedangakan dalam fraksi aquades memperlihatkan bahwa komponen paling dominan adalah peak ke 1 dan 2 dengan presentase 87,42\% dan 12,56\%. Hasil identifikasi senyawa total dalam ekstrak metanol teridentifikasi 7 puncak sehingga diduga puncak-puncak yang larut kedalam fraksi air adalah puncak 2, 3, 4 dan 5. Sedangkan puncak 1, 6 dan 7 diduga larut kedalam fraksi diklorometana. Dugaan ini didasarkan pada besarnya persen area kromatogram senyawa yang teridentifikasi pada fraksi aquades. Selain itu, kekuatan kepolaran antara kedua pelarut yang digunakan untuk fraksinasi diketahui aquades lebih polar dibandingkan diklorometana sehingga senyawa-senyawa metabolit yang polar akan cenderung larut didalam fraksi aquades. Sedangakan senyawa metabolit yang kurang kepolarannya akan cenderung larut didalam fraksi diklorometana. Senyawa-senyawa yang telah dilaporkan dan berhasil diisolasi dari daun tumbuhan sirsak adalah senyawa golongan flavonoid, fenilpropanoid, polikatida, fenol, tannin, terpenoid, lakton, kardiak glikosida, fitosterol serta alkaloid (Moghadamtousi et al, 2015).

Berdasarkan penggolongan senyawa yang telah berhasil diisolasi maka dapat diasumsikan bahwa senyawa-senyawa yang teridentifikasi pada KCKT pelarut diklorometana adalah senyawa golongan fenol, polikatida, tannin dan alkaloid. Hal ini disebabkan karena senyawasenyawa ini cenderung larut dalam pelarut organik yang bersifat semipolar 
maupun polar. Sedangkan senyawa yang teridentifikasi KCKT pada pelarut air diduga adalah senyawa polar yang terikat dengan suatu gugus glikosida. Hasil identifikasi ini, menjadi dasar informasi untuk langkah penelitian lanjutan.

\section{SIMPULAN}

Ekstraksi senyawa pada daun tumbuhan sirsak menggunakan metanol dan partisi dua pelarut yang berbeda kepolaran dihasilkan senyawasenyawa yang berbeda dalam tiap pelarut didasarkan pada kelarutan dan kepolarannya terhadap pelarut yang digunakan. Senyawa-senyawa yang teridentifikasi pada KCKT pelarut diklorometana adalah senyawa golongan fenol, polikatida, tannin dan alkaloid, Sedangkan senyawa yang teridentifikasi KCKT pada pelarut air diduga adalah senyawa polar yang terikat dengan suatu gugus glikosida. Perlu dilakukan teknik pemisahan lanjutan sehingga diperoleh senyawa murni dari tiap pelarut dan uji bioaktivitasnya.

\section{PUSTAKA}

Astuti R., Soekardi H. 2014. Pengaruh Ekstrak Daun Sirsak (Annona muricata L.) Terhadap Mortalitas Kecoa Amerika (Periplaneta americana) Dewasa. Seminar Nasional Pengembangan Teknologi Pertanian (Hal.1-7). Lampung:Politeknik Negeri Lampung.

Bories C., Loiseau P., Cortes D., Myint S.H., Hocquemiller R., Gayral P., Cave A., \& Alain L.,.1990. Antiparasitic Activity of Annona muricata and Annona cherimolia Seeds. Planta Med. 434-436.

Chang R., Liaw C., Lin C., Chui H., \& Wu Y. 2003. New Adjacent BisTetrahydrofuran Annonaceous acetogenins from Annona muricata. Planta Med, 241-246.

Fessenden \& Fessenden. (1997). Kimia Organik, Edisi kedua jilid 1 dan 2, Alih bahasa A.H. Pudjaatmaka. Surabaya: Erlangga.

Harborne J.B. 1987. Metode fitokimia: Penentuan cara moderen menganalisis tumbuhan, terbitan kedua terjemahan Kosasih Padmawinata dan Iwan Soediro. Bandung: ITB Press.

Harborne, J.B. 1993. The Flavonoids, Advances in Research Since 1986. London: Ed. London: Chapman and Hall.

Kim G., Zeng L., Alali F., Rogers L., Wu F., Soelaksono S., \& Mclaughlin J.1998. Muricoreacin And Murihexocin C, MonoTetrahydrofuran Acetogenins From The Leaves Of Annona Muricata. Phytochemistry, Vol. 49 No , 565-571.

Kristanti N., Nanik S., Mulyadi T., Bambang K. 2008. Fitokimia. Surabaya: Airlangga University Press.

Liaw C., Chang F., Lin C., Chou C., Chiu H., Wu M., Wu Y. 2002. New Cytotoxic Monotetrahydrofuran Annonaceous Acetogenins from Annona muricata. J. Nat. Prod, 470-475.

Moghadamtousi Z., Mehran F., Sonia N., Gokula M., Hapipah M., Habsah A. 2015. Annona muricata (Annonaceae): A Review of Its Traditional Uses, Isolated Acetogenins and Biological Activities. Int. J. Mol. Sci.16 , 15625-15658.

Salaki C., \& Jantje P. 2012. Pemanfaatan Baringtonia Asiatica Dan Annona Muricata Terhadap Serangga Vektor Penyakit Pada Tanaman Cabai. Eugenia Volume 18 No. 22-34.

Siswarni M., Nurhayani, Suci D. 2016. Ekstraksi Acetogenin Dari Daun Dan Biji Sirsak (Annona muricata L) Dengan Pelarut Aseton. Jurnal Teknik Kimia USU, Vol. 5, No. 2, 1-4.

Skoog. 1998. Principle of Instrument analysis. Singapore: Thomson Learning Inc.

Sumantri I., Galih P., Hendrawan L. 2014. Ekstraksi Daun Sirsak (Annona Muricata L) Menggunakan Pelarut Etanol. Momentum, Vol. 10, No. 1 , Hal. 34-37.

Tenrirawe A. 2011. Pengaruh Ekstrak Daun Sirsak Annona Muricata L Terhadap Mortalitas Larva Helicoverpa armigera H. Pada Jagung. Seminar Nasional Serealia , 521-529.

Venkataraman. 1972. Review article wood phenolics in the chemotaxonomy. Phythochemistry, 1-16.

Zeng L., Wu F., Nicholas O., Jerry M. 1996. Five New Monotetrahydrofuran Ring Acetogenins from the Leaves of Annona muricata. J. Nat. Prod. 59 , 1035-1042. 